DOI: 10.19195/0137-1150.167.49

\author{
GALINA NEFAGINA
}

Akademia Pomorska w Słupsku, Polska

\title{
Танатологические хронотопы в романе Евгения Водолазкина Авиатор
}

Феномен смерти, являясь одним из ключевых понятий онтологии, определяет проблематику многих произведений как русской классической, так и современной литературы. В поисках смысла жизни русская литература так или иначе обращалась к теме смерти, исследуя ее в аксиологическом и экзистенциальном аспектах, видя в ней основу мифотворчества, отражая психологию осознанных и бессознательных рефлексий человека, стоящего перед лицом смерти. В литературе XXI века, обогащенной постмодернистской практикой представления смерти как кода культуры, обладающего множественностью интерпретаций, танатологические мотивы вписываются в пространство моделирования образа смерти, осознания неизбежности ее и отношения к ней современного человека. Девальвация ценности человеческой жизни и нивелирование смерти в постмодернистской культуре, снятие ее сакрального смысла и травестирование ее трагического модуса преодолеваются в современной русской литературе, опять обратившейся к человеку как мере всего сущего. Примером произведения, основу которого составляет тема умирания и смерти, является роман Евгения Водолазкина Авиатор (2016).

Особенность сюжетостроения романа Авиатор состоит в движении от смерти к жизни и затем опять к смерти. Но и первая смерть героя не отражена как образ телесного прекращения жизни, и вторая смерть дается как бестелесное событие через образ терпящего катастрофу самолета, в котором летит герой Иннокентий Платонов. Ни в первом, ни во втором случае явление смерти не фиксируется как образ мертвого тела или как констатация прекращения жизни.

Сюжет построен по принципу перевернутой параболы, ветвь которой устремляется вверх и, достигнув апогея, нисходит вниз. Он начинается с выхода Иннокентия из состояния смерти-анабиоза, в которое он был 
погружен замораживанием в 1930-е годы, когда, как пишет автор, проводились опыты по искусственному замораживанию с целью позднейшего оживления, или воскрешения. Опыты проводились на добровольцах-лагерниках, которых называли лазарями, по аналогии с библейским сюжетом о воскрешении Лазаря через четыре дня после его смерти. Мотив воскрешения Лазаря, вернее, мифологема, является сквозной и определяет танатологическую концепцию произведения. Процесс познавания Платоновым новой действительности, в которой он очутился спустя более семи десятков лет, процесс осознания себя-в-мире представляет собой восхождение к обретению собственной личности. Это процесс восстановления событий, которые происходили в жизни Платонова до замораживания, вспоминания запахов, звуков прежней жизни и, конечно, людей, которые встречались на его пути. Высшей точкой воскрешения является любовь к Анастасиимладшей, Насте, и зачатие, за-рождение [выделено мною. - Г. Н.] ребенка, то есть воскрешение себя в другом человеке. После этого начинается схождение к смерти, которое симметрично процессу воскрешения. Такое сюжетостроение отражает концепцию онтологической бытийственной непрерываемости жизни при онтической конечности ее.

Ключом к пониманию философского смысла романа является замечание о том, что Лазарь после воскрешения „никогда не улыбался. Значит, он увидел там то, в сравнении с чем никакие земные дела больше не вызывали эмоций"1. Но ведь увидел что-то! Значит, смерть не есть конец жизни, а лишь конечность этого [выделено мною. - Г. Н.] существования.

Возникает вопрос: случайно ли герой носит фамилию Платонов? Если учесть, что писатель Андрей Платонов в своей концепции жизни и смерти испытывал сильное влияние философии „общего дела” Николая Федорова, согласно которой целью человечества должна стать работа по воскрешению умерших, то очевидна смысловая наполненность фамилии героя. Платонов-персонаж - современник писателя Платонова, а 1930-е годы, когда он стал невольным участником эксперимента — время наиболее интенсивных исследований по преодолению смерти, время утопических проектов бессмертия. Таким образом, роман Водолазкина, реализуя утопический проект, представляет своего рода антиутопию. Только это не привычная для русской литературы социальная или технократическая, а экзистенциально-танатологическая антиутопия.

На такое определение жанровой формы Авиатора наталкивают несколько моментов поэтики романа, характерных для антиутопии. Во-первых, действие развивается после экстраординарного события, каким в романе является замораживание Платонова. Во-вторых, идея сохранения жизни путем замораживания организма коррелирует с утопическими проектами XX века,

${ }^{1}$ Е. Водолазкин, Авиатор, Москва 2016, с. 383. Далее цитируется по этому изданию с указанием страниц в тексте в скобках. 
а конечным результатом оказывается смерть героя. В-третьих, смыслообразующим топосом романа является остров, то есть, пространство ограниченное, замкнутое, как это присуще антиутопии. Для романа Водолазкина это не реальное пространство, а пространство ощущений героя, который живет в двух измерениях: больница, затем квартира - в его действительности, и книжный остров Робинзона из его детства и Соловецкие острова его лагерного существования - в его воспоминаниях. Платонов, будучи окружен людьми, одинок, как Робинзон на острове - он вынут из своего времени. Неслучайно слова о герое его детства воспринимаются как описание его, платоновского, положения в этом новом для него мире.

Родившее его время осталось где-то далеко, может быть, даже ушло навсегда. Он теперь в другом времени - с прежним опытом, прежними привычками, ему нужно либо их забыть, либо воссоздать весь утраченный мир, что очень непросто [c. 42].

Если классические танатологические сюжеты традиционно сводятся к воспроизведению именно умирания, то толчком к развитию романа Водолазкина является процесс воскрешения. Но чтобы воскреснуть, надо умереть. Значит, в начале всего была все-таки смерть, хотя она не обозначена в тексте.

В романе представлено несколько типов смерти. Один из них - мнимая смерть, притворство. Впервые мотив мнимой смерти возникает в воспоминании о детстве в Алуште, когда мальчик наблюдал, как взятые в руки жуки и гусеницы притворялись мертвыми, чтобы выжить. Отсюда нить протягивается к лагерным годам, когда ,хотелось притвориться мертвым чтобы меня вот так же положили на траву и больше не трогали. Так ведь не верили, ждали смерти всерьез” [с. 138]. В лагере появилась привычка замирать (почти умирать), заслышав чьи-то шаги. Когда Платонову предлагают стать подопытным лазарем, то выбор для него не между жизнью и смертью, а между смертью и смертью. Академик Муромцев прямо говорит, что если Платонов останется в лагере на общих условиях, то умрет, но и замораживание - тоже путь к смерти. Но, может, это будет мнимая смерть? Надежда на жизнь в будущем крошечная, только измученному телу уже все равно: „все пути ведут к смерти” [с. 216], - без эмоций произносит Платонов. Таким образом, лагерь, в котором сжимается время жизни человека, является хронотопом реальной смерти.

Показательно, что лагерь — это топос и смерти от замерзания (смерть Васи и тысяч лагерников), и возможной жизни - утопической попытки достижения бессмертия путем замораживания объекта (т. е. замерзания субъекта - Платонова). Замерзание здесь ключевое слово. Это подтверждают слова Платонова, записанные, правда, по другому поводу: „одним и тем же именем могут обозначаться полные противоположности” [с. 162]. Но и в том, и в другом случае (смерть от замерзания и жизнесмерть при замораживании) „время как бы исчезало, и сам ты проваливался в иную 
действительность” [с. 149]. Исчезновение времени - важная черта танатологического хронотопа. Значит, замораживание - все та же смерть, т. к. время для Платонова остановилось, исчезло его движение. Он как будто был вынут из времени. Но стоит обратить внимание на мысль Платонова о том, что лишенные и времени, и пространства - мертвецы. Ведь Платонов был изъят только из своего времени, как только из своего пространства [выделено мною - Г. Н.] был изъят Робинзон — тоже сквозной образ романа. Тогда „получается, что мы с Робинзоном - полумертвые” [c. 297]. Жизнь и смерть оказываются неразрывно связанными с пространством и временем. Неслучайно в рассуждения героя, пытающегося восстановить свою прежнюю жизнь, а, значит, и собственное „я”, вписывается имя Бахтина, чьи исследования хронотопа составляют основу изучения времени-пространства в литературе. Гейгер приносит книги Бахтина Платонову, а Настя, прочитав работы ученого, называет „лишенных времени и пространства хронотоплес" [с. 297], то есть, хронотоплес - это мертвецы, замученные и замерзшие в лагерях Соловецких островов.

Топос лагеря оказывается связанным с более широким по содержанию хронотопом острова, которым определяется во многом философская концепция жизни и смерти в романе. Жизнь метафорически уподобляется острову среди моря, по солнечной дорожке которого летают ангелы. Остров в детстве - это гармония Петербурга, о стены которого разбивались волны хаоса. Это крымская Алушта, где в 1911 году в Профессорском уголке отдыхали родители вместе с Платоновым. Но это и книжный необитаемый остров Робинзона, вынужденного строить свою жизнь из материальных обломков цивилизации, как воскрешенный Платонов вынужден строить свою личность из „обломков” звуков и запахов прошлого, из осколков отраженных в памяти слов, лиц, событий. В той же метафоре жизни как острова посреди моря содержится и метафора смерти как исчезновения солнечной дорожки, „и что на месте этой красоты начнется, никому не известно. И кто там будет вместо ангелов летать, тоже неизвестно. [...] Страшна сама мысль о погружении во мрак, она сжимает сердце, как тиски" [с. 62]. Остров детства - это место, где нужно жить. Остров взрослого Платонова - это место, где нужно выжить, так же, как и в лагере.

Меня раз за разом спрашивают, как я выживал в лагере. Имеют в виду не только физическую сторону жизни, но и ту, что делает человека человеком. Вопрос законный, потому что лагерь - ад не столько из-за телесных мучений, сколько из-за расчеловечивания многих, туда попавших. Чтобы не позволить истребить в себе остатки человеческого, нужно этот ад хоть на время покидать - хотя бы мысленно. Думать o Pae [c. 163].

Мысль о Рае, о том, что жизнь души не заканчивается с умиранием тела — это христианская концепция смерти. Христианство 
пыталось освободить человека от угрозы уничтожения обещанием жизни после смерти. Но вместе с тем рождается острое переживание собственного личного бытия. Ощущение индивидуальной неповторяемой судьбы, естественно, было сопряжено с трагическим смятенным ощущением завершения уникальной жизни ${ }^{2}$.

В романе есть еще один концептуально значимый диалог:

— Ты веришь в Бога?

- Да.

— В эпоху аэропланов стыдно быть верующим [...]:

- Разве аэропланы отменили смерть? [с. 91].

Если есть смерть, то необходима вера в Бога, в Царствие небесное, в то, что после исчезновения солнечной дорожки ангелы все же будут летать. Так танатологический хронотоп Рай — это место тишины, по представлению Платонова, и отсутствия времени. В Раю нет событий, есть только явления.

Если с христианской точки зрения смерть физическая не есть абсолютный конец, а только продолжение жизни души в ином мире, и это может служить утешением, то безрелигиозного человека смерть страшит как конечность его личного, индивидуального бытия. Это естественная реакция, но у лагерников смерть уже не вызывает страха, они безразличны к ней, и смерть представляется освобождением от физических мучений, ибо „человек имеет свои пределы" [с. 68]. Платонов вспоминает, как завидовал тем, кто замерзал на лесоповалах и кого эта [выделено мною.- Г. Н.] жизнь уже не касалась. Смерти не боялись еще и потому, что она стала обыденностью. „Нельзя сказать, что за своими жертвами смерть в наши бараки приходила: она в них жила" [с. 301]. Смерть в лагере была результатом насилия государства [выделено мною - Г. Н.] над личностью, но ее хронотоп отличается от хронотопа насильственной смерти, совершенной конкретным убийцей.

Насильственная смерть — это второй тип смерти, представленный в романе. На вокзале пьяные матросы убивают отца Платонова, кто-то, до поры не известный, убивает на берегу реки Зарецкого, в 1937 году в ГПУ расстреливают Севу, начальник лагеря расстреливает генерала Миллера. Топика насильственной смерти разнообразна, время всегда неожиданно для погибающего. В хронотопе такого типа смерти константой является внезапность, непродолжительность времени, пространство не имеет определенного характера.

Образ насильственной смерти напрямую связан с типом поведения человека, стоящего на краю жизни, и определяет не только характер этого человека, но и отражает авторскую оценку его. Так, безвинно убитый отец живет в памяти сына как „любимый белоснежный папа” [c. 52], что отсылает к библейским белым одеждам. Бывший друг детства Сева, слабый,

${ }^{2}$ П. Гуревич, Жница с косой: Жизнь после смерти, [в:] О смерти и бессмертии, сост. П. Гуревич, Москва 1991, с. 13-14. 
всегда оказывавшийся на вторых ролях и из зависти предавший Платонова, отправив его на Соловки, сам оказался жертвой репрессий. В протоколах допросов ,подробно рассказывалось, что говорил Сева, вымаливая себе жизнь, как громко, по-бабьи рыдал и бросался целовать сапоги следователям" [с. 332]. Смерть души Севы наступила гораздо раньше смерти его тела, которой он и боялся, и уже желал как прекращения мучений.

Как антитеза такому поведению предстает сцена смерти генерала Миллера. Начальник лагеря убивает его тоже из зависти:

[...] шел он не ко мне, а к Миллеру, образцу порядка и подтянутости. Наметанным глазом Ногтев сразу заметил того, кем сам он стать никогда не смог бы. Приближался в своей кожанке пружинящей походкой, шпана шпаной. На ходу доставал наган. [...] Миллер спокойно смотрел на Ногтева. Поправил вещмешок на плече, и в этом движении не было ни суеты, ни страха [с. 135].

Эпизоды насильственной смерти отца и Миллера симметричны по смыслу и содержанию. Убийцы во всех случаях представлены как духовно не развитые существа, у которых инстинкт жажды превосходства и, следовательно, насилие как основа выживания доминирует над понятиями чести и гуманности. Смерть обнажает истинную сущность человека: отец Платонова и генерал принимают ее достойно.

Симметричны и два других танатологических эпизода - расстрел Севы и убийство Зарецкого. Только здесь убиты вовсе не безвинные жертвы. Оба слабые, завистливые, трясущиеся от страха за жизнь доносчики. Закономерно, что стремившийся успеть за „локомотивом истории” [с. 334] Сева, ставший косвенным убийцей Платонова, сам попал под колеса этого „локомотива". Но убийца Зарецкого Платонов — человек духовный. Как же объяснить роль палача, которую он взял на себя? Уже воскрешенный Платонов вспоминает убийство Зарецкого во всех подробностях своих тогдашних ощущений. Тогда им руководило чувство справедливой мести Зарецкому за донос на отца Анастасии. Платонов и орудием убийства избрал статуэтку Фемиды как символ правосудия, хотя сам он говорит, что просто фигурка была удобной для руки. Но ведь об этом он говорит, уже испытывая вину и пытаясь отвергнуть любое оправдание убийства. Платонов мучается совершенным убийством так же, как Раскольников. Знаковым намеком на Достоевского, своеобразной репликой Преступления и наказания (1866) является фраза о статуэтке за пазухой, которая „была холодной, как топор” [c. 405], когда Платонов шел по Ленинграду (Петербургу) убивать Зарецкого. Чувство вины Платонов не может избыть покаянием перед батюшкой, который советует не у него, а у убитого попросить прощения и покаяться.

В контексте вины и раскаяния важны размышления Платонова над тем, для чего Бог воскресил Лазаря. „Может быть, Лазарь понял что-то такое, что понять можно было, только умерев? [...] Может быть, на нем был тяжкий грех, исправить который можно, лишь будучи живым, - и для того он был 
воскрешен?" [с. 382-383]. Воскрешенный Платонов, воспринимавший прежде Зарецкого как отвратительную рептилию, попытался понять этого человека. Неслучайно написанный им портрет Зарецкого наполнен трагизмом.

Сидящий оплакивает нечто (может быть, свою жизнь), и водка с колбасой — тому единственные свидетели. Черты лица тонки. Плечи сутулы.

Пока он молчит, облик его возвышен - таков, возможно, каким задумывался. А Зарецкий молчит. Не слышно его блеяния, гадких слов.

И думаешь: мысли, в которые он погружен, высоки. А колбаса - так, суровая необходимость. Потребность тела.

Он на нее и не смотрит. Фокус его взгляда где-то за пределами этой комнаты, может быть, за пределами видимого мира вообще [с. 384].

Рисунок Платонова - это и прощение доносчика Зарецкого, и просьба о прощении у Зарецкого. Воскрешенный Платонов, как Лазарь, сумел понять что-то, что было недоступно для понимания при жизни.

Таким образом, в романе Водолазкина вокруг насильственной смерти образуется целый комплекс философских, этических и религиозных проблем.

Естественная смерть связана со старостью и болезнями. Так умирает Остапчук, мать Анастасии, Анастасия, Терентий Осипович Добросклонов, мама Платонова. Топосами естественной смерти, характерными не только для романа Водолазкина, являются больница, дом престарелых, кладбище, домашний круг близких людей. Это одновременно и танатологические хронотопы, поскольку место оказывается тесно связанным с присущим ему временем умирания, угасания, ухода жизни и из жизни. На кладбище, месте упокоения умерших, „не чувствовалось никакой печали. Даже смерти не чувствовалось” [с. 300]. Определение времени в танатологическом хронотопе естественной смерти дается Платоновым метафорически: „они умерли еще тогда, когда можно было заказать ограду" [с. 80], что указывает на спокойное, без внешних потрясений время смерти.

Особенным танатологическим хронотопом романа является самолет. Он связан со сквозным образом авиатора. Авиатор - это и летчик аэроплана в детстве Платонова, и сам Платонов, который чувствует себя авиатором, и некий абстрактный авиатор, который может сверху взглянуть на мир и охватить все разом.

Между авиатором Фроловым и Платоновым существует судьбоносная связь. Ребенком Платонов, восхищенный смелостью и свободой пилота, решает стать авиатором.

Меня завораживало само слово - авиатор. Его звучание соединяло в себе красоту полета и рев мотора, свободу и мощь. Это было прекрасное слово. Позднее появился „летчик”, которого будто бы придумал Хлебников. Слово неплохое, но какое-то куцее: есть в нем что-то от воробья. А авиатор - это большая красивая птица. Такой птицей хотел быть и я. Авиатор Платонов. Это стало не то что бы домашним именем, но время от времени меня так называли. И мне это нравилось [с. 92]. 
Позже Платонов, записывающий все, из чего состояла его жизнь до замораживания, вспоминает, как перед полетом подумал о смерти Фролова, а через несколько минут стал свидетелем его трагической гибели. Какая-то незримая нить соединила их судьбы в одинаковой смерти. Когда аэроплан авиатора Фролова поломал крыло, и летчик летел к своей смерти,

Мгновения его полета все длились и длились, и я успел подумать, что так продлевается его жизнь, что сейчас я вижу его живым, а спустя миг он будет мертвым... Я приготовился поймать грозный миг перехода жизни в смерть, но ничего, конечно же, не поймал [с. 271].

Здесь показательно восприятие времени одной протяженности в двух ракурсах: длительность мгновений для жизни и краткость мига для перехода в смерть. Таковы же темпоральные характеристики хронотопа для ситуации с катастрофой самолета, на котором летел Платонов. Смерть „принимает контуры [...] садящегося без шасси самолета" [с. 407]. Платонов погибает как авиатор, и эта смерть оказывается своего рода спасением от физического распада.

Воскрешение Платонова, физическое тело которого было сохранено, связано с восстановлением души через воскрешение в памяти нематериальных ощущений - запаха, вкуса, звука, цвета, а от их припоминания уже протягивалась ниточка к воссозданию событий, лиц, в конечном счете своего „,”, ведь человек - это все, что его окружает и что проходит через его чувства и сознание.

Умирание Платонова показано как потеря материальных - физических - функций: ослабевают ноги, не могут удержать предмет руки, а затем начинается забывчивость, угасание оперативной памяти, то есть происходит процесс, зеркально симметричный воскрешению.

Постепенное угасание физической жизни Иннокентия дается в восприятии и наррации трех персонажей - самого Платонова, Насти и врача Гейгера. Записи Гейгера и Насти дополняют дневник Платонова, ставят иные акценты в описании событий жизни героя.

В книге $O$ смерти и умирании Элизабет Кюблер-Росс выделяет пять стадий психологического состояния умирающего человека. Первая - это отрицание, когда человек не хочет допускать мысли о собственной смерти. Вторая - злость и гнев, которые испытывает умирающий. Затем идут попытки заговорить судьбу, депрессия и - последняя стадия - принятие неизбежности смерти и стремление максимально использовать оставшееся время ${ }^{3}$. Этот танатологический комплекс своеобразно прослеживается в процессе умирания Платонова, метафорически выраженного в „легком, не обвальном пока увядании" [c. 320] осени. Осень - время и пространство танатологического хронотопа умирания.

3 Э. Кюблер-Росс, О смерти и умирании, пер. К. Семенов, В. Трилис, Москва 2001. 
Уже побывав однажды за пределами жизни, ни отрицания смерти, ни гнева Платонов не испытывает. Эти чувства переданы Насте. Платонов же, для которого „смерть в лагере казалась выходом, а сейчас она кажется уходом. Уходом от тех, кого люблю" [c. 367], чувствует депрессию, которую он тщательно скрывает, отчаяние и страх. Только корни этого страха не столько в потери своей жизни, сколько в ответственности за жену и еще не родившуюся дочь.

Отношение к смерти обусловлено тем, насколько ценна жизнь. Смерть подступает, когда у Платонова появляется дом, любимая и любящая жена, ожидание будущей дочери, когда, как он сам определяет, появляется в жизни радость. Тем страшнее потеря всего этого с уходом из жизни. И записки, вернее, жизнеописание Платонова ставят целью сохранить его [выделено мною. - Г. Н.] воспоминания, чтобы не было „прошлое отрезано от настоящего" [c. 349], чтобы оно продолжилось в реальной жизни. У Водолазкина (и в этом его концепция совпадает с концепцией Михаила Шишкина) написанное слово преодолевает смерть, так как записанный твой мир становится миром другого, читающего эти записки.

\section{Михаил Бахтин писал:}

Помыслить мир после моей смерти я могу, конечно, но пережить его эмоционально окрашенным фактом моей смерти, моего небытия уже я не могу изнутри себя самого, я должен для этого вжиться в другого или других, для которых моя смерть, мое отсутствие будет событием их жизни ${ }^{4}$.

Платонов думает, что если бы Настя могла так „вжиться” в его мир, „научилась находить и описывать вещи, мне соответствующие, моя жизнь могла бы продолжаться и в мое отсутствие" [с. 372].

Платонов понимает смерть по-христиански: „Смерть не нужно рассматривать как прощание навсегда. Она - временное расставание” [c. 375]. Он верит в вечность души, и эта вера позволяет ему не терять чувства достоинства перед лицом смерти. Даже в момент аварии самолета он продолжает описывать мельчайшие детали своей жизни, которые оказываются важными для вечности.

Водолазкин оставляет открытым финал романа: службы аэропорта готовятся к посадке самолета, не выпустившего шасси, но сел ли он или разбился, не сказано. Но это и не важно. Финал жизни героя уже предопределен, и изображение самого момента смерти не функционально в контексте жизнеописания.

Применительно к танатологической ситуации Платонова можно говорить о хронотопе умирания. В отличие от хронотопа смерти, где при тесной связи времени-пространства номинирована пространственная координата (больница, кладбище, самолет), хронотоп умирания авиатора Платонова не содержит выраженной пространственной характеристики. Пространство

${ }^{4}$ М. Бахтин, Автор и его герой в эстетической деятельности, Москва 2000, с. 128. 
его - это пространство записей, а время - осень, пора увядания. Отношение Платонова к своей приближающейся смерти запечатлено в его дневнике и записках. Пережитый Платоновым опыт жизнесмерти и воскрешения позволяет понять, что

те, кто жили вечностью, особо ценили время. И даже не столько время, сколько его непрерывность, отсутствие дыр. Думали, может быть, что настоящая вечность только и наступает, что после внимательно прожитого времени [с. 387].

„Внимательно прожитое время” включает все стороны бытия личности, для который ценны не только и, может быть, не столько события большого мира, сколько события близкого круга, данные в ощущениях запаха, цвета, звука, детских воспоминаний. Записи Платонова — ровесника века призваны восполнить тот провал во времени, который образовался в пространстве индивидуальной жизни человека после революции, принесшей глобальные проекты, коллективное обще-житие (разделено мною. - Г. Н.) и вырвавшей человека из его личной жизни, из родовой преемственности, которая обеспечивала жизнь вечную.

Таким образом, в романе Водолазкина Авиатор разным типам смерти соответствуют разные танатологические хронотопы. Характер пространственно-временных отношений в реализации мотива смерти отражает комплекс философских (онтологических и аксиологических), этических, религиозных проблем, связанных с вечной темой смерти.

\section{Библиография}

Бахтин М., Автор и его герой в эстетической деятельности, Москва 2000.

Водолазкин Е., Авиатор, Москва 2016.

Гуревич П., Жница с косой: Жизнь после смерти, [в:] О смерти и бессмертии, сост. П. Гуревич, Москва 1991.

Кюблер-Росс Э., О смерти и умирании, пер. К. Семенов, В. Трилис, Москва 2001.

\section{Thanatological chronotopes in Eugeny Vodolazkin's novel Aviator}

\section{Summary}

Eugeny Vodolazkin's novel is based on thanatologic motives. Eternal literary theme enables to realize (represent) the author's concept of death. The article deals with peculiar features of the plot, types of death representation and types of thanatologic chronotope connected with them. The plot is as an inverted parabola, the branch of which tends upwards and reaching its apogee to life (resurrection) and tends to death again. It is possible to define types of fictitious and real death, natural and brutal, physical and spiritual. Different thanatological chronotopes correspond to dif- 
ferent types of death. Time-space relation makes it possible to show the summation of ontological, axiological, ethical and religious sides of thanatological issues.

Keywords: thanatological motives, chronotop, time-space, death, a parabola, a typology of death

\section{Танаталагічныя хранатопы ў рамане Яўгена Вадалазкіна Авіятар}

Рэзюмэ

Раман Яўгена Вадалазкіна збудаваны на танаталагічных матывах. Вечная для літаратуры тэма дае магчымасць рэалізацыі аўтарскай канцэпцыі смерці. У артыкуле разглядаюцца асаблівасці сюжэту, тыпы рэпрэзентацы смерці і звязаныя з імі тыпы танаталагічных хранатопаў. Сюжэт пабудаваны па прынцыпе перавернутай парабалы, галіна якой імкнецца ўгору i, дасягнуўшы апагею, сыходзіць уніз. Асаблівасцю сюжэта рамана Авіятар з'яўляецца рух ад смерці да жыцця (уваскрашэнне) і затым зноў да смерці. Вылучаюцца тыпы ўяунай і рэальнай смерці, натуральнай і гвалтоўнай, фізічнай і духоўнай. Розным тыпам смерці адпавядаюць розныя танаталагічныя хранатопы. Суадносіны часу-прасторы дазваляюць адлюстраваць комплекс анталагічных, аксіалагічных, этычных і рэлігійных бакоў танаталагічнай праблематыкі.

Ключавыя словы: танаталагічныя матывы, хранатоп, час-прастора, смерць, парабала, тыпалогія смерці 